\title{
Alelopatia: feijão-caupi e feijão-mungo-verde interferem na germinação e desenvolvimento inicial de pepino (Cucumis sativus
}

L.)?

Um dos principais fatores responsáveis por decréscimos nos rendimentos produtivos na agricultura, que por consequência compromete na produção de alimentos, são as plantas daninhas. Atualmente, o meio usual de manejo para essas plantas invasoras está no uso do controle químico. Entretanto, a busca por meios mais sustentáveis para contribuir com o manejo alternativo desses ambientes estão constantemente sendo estudados, com destaque para o estudo da alelopatia, que pode contribuir significativamente como uma das formas promissoras de manejo ecológico de plantas daninhas nos agroecossistemas. Diante disso, objetivou-se com a pesquisa, avaliar o potencial alelopático de feijão-caupi (Vigna unguiculata L.) e feijão-mungo-verde (Vigna radiata L.) na germinação e desenvolvimento inicial da cultura do pepino. Para a elaboração do experimento em laboratório, utilizou-se o delineamento inteiramente casualizado em esquema fatorial $2 \times 4$. Os fatores foram constituídos por duas espécies de feijões e quatro concentrações do extrato dos grãos ( $0 \%, 7,5 \%, 15 \%, 30 \%)$, sendo os tratamentos formados pela combinação dos fatores estudados, constituídos por 4 repetições para cada tratamento. Foi observado potencial alelopático para todas as espécies estudadas, sendo o extrato de feijão-caupi o mais prejudicial para todas as variáveis analisadas, consistindo no mais promissor em estudos sobre o manejo ecológico.

\section{Allelopathy: beans-caupi and beans-mungo-green interfer in germination and initial development of cucumber (Cucumis sativus L.)?}

One of the main factors responsible for decreases in agricultural production products, which affect food production, are weeds. Currently, the usual means of management for these invasive plants is the use of chemical control. However, the search for more sustainable ways to contribute to the alternative management of these environments is constantly being studied, with emphasis on the study of allelopathy, which can contribute significantly as one of the promising forms of ecological management of weeds in agroecosystems. Therefore, the objective of the research was to evaluate the allelopathic potential of cowpea (Vigna unguiculata L.) and green mung bean (Vigna radiata L.) in the germination and initial development of the cucumber culture. For the elaboration the experiment in the laboratory, a completely randomized design in a $2 \times 4$ factorial scheme was used. The factors were constituted by two species of beans and four concentrations of the extract of the seeds $(0 \%, 7.5 \%, 15 \%, 30 \%)$, being the treatments formed by the combination of the studied factors, constituted by 4 repetitions for each treatment. Allelopathic potential was observed for all studied species, with cowpea extract being the most harmful for all analyzed variables, consisting of the most promising in studies on ecological management.

Keywords: Germination; Concentration; Metabolites; Seedling development.

Topic: Proteção de Plantas e Fitotecnia

Reviewed anonymously in the process of blind peer
Received: 06/05/2020

Approved: 04/06/2020
Adriano Maltezo da Rocha (iD)

Universidade do Estado de Mato Grosso, Brasil http://lattes.cnpq.br/0322584934720610 http://orcid.org/0000-0002-0032-0034

admr.maltezo@hotmail.com

Eslaine Camichele Lopes (iD)

Universidade do Estado de Mato Grosso, Brasil http://lattes.cnpq.br/7804839411901883 http://orcid.org/0000-0001-8924-050X

eslainelopes61@gmail.com

Sabrina Cássia Fernandes (iD

Universidade do Estado de Mato Grosso, Brasil http://lattes.cnpq.br/6447479607197205 http://orcid.org/0000-0001-8092-8340 sabrinacassia1999@hotmail.com

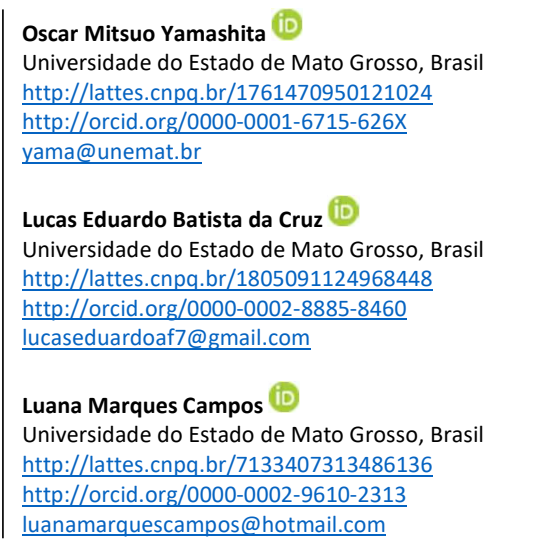

Willian Tsuyoshi Kume (iD

Universidade do Estado de Mato Grosso, Brasil http://lattes.cnpq.br/1643792753107063 http://orcid.org/0000-0001-5009-6862 williankume@hotmail.com
Referencing this:

ROCHA, A. M.; LOPES, E. C.; FERNANDES, S. C.; YAMASHITA, O. M.; CRUZ, L. E. B.; CAMPOS, L. M.; KUME, W. T.. Alelopatia: feijão-caupi e feijão-mungo-verde interferem na germinação e desenvolvimento inicial de pepino (Cucumis sativus L.)?. Revista Ibero Americana de Ciências Ambientais, v.11, n.4, p.59-71, 2020. DOI: http://doi.org/10.6008/CBPC2179-6858.2020.004.0005 


\section{INTRODUÇÃO}

Atualmente, com a necessidade de buscar melhores rendimentos produtivos no campo para solucionar problemas do crescente aumento populacional, inúmeros fatores são responsáveis pelos decréscimos do potencial produtivo das culturas de interesse, e um dos principais, está na presença de plantas daninhas (CREMONEZ et al., 2013).

O aparecimento de plantas daninhas nos sistemas de cultivos, atuam diretamente no aumento da mão-de-obra, uso intensivo de herbicidas, dificuldade de práticas de manejo e entre outros. Enquanto que indiretamente, a presença dessas plantas no campo, faz com que potencialize o aparecimento de pragas e doenças por muitas serem hospedeiras alternativas, competição pelas condições ambientais com a cultura de interesse econômico, decréscimo produtivo e por consequência elevação de custos de produção (ZIMDAHL, 2007; PEREIRA et al., 2018).

Mesmo observando que existe contribuições significativas para a produtividade no campo com o uso de herbicidas, medidas alternativas precisam serem tomadas, buscando associar técnicas convencionais juntamente com medidas alternativas para o aumento da sustentabilidade dos sistemas (MAULI, 2009). Para isso, a busca por estudos com espécie com potencial alelopático passa a ser uma dessas alternativas para implementação nesses sistemas.

A alelopatia, consiste em um fenômeno biológico ocasionado pela exsudação de substâncias químicas por plantas presentes nos ambientes "fontes", que resultam em efeitos na estimulação (alelopatia positiva) ou inibição (alelopatia negativa) da germinação e desenvolvimento de outros vegetais presentes próximos "drenos" (SANTOS et al., 2010). Os compostos químicos produzidos pelas plantas são inúmeros, estando presentes em diferentes concentrações e órgãos das plantas, podendo ser em folhas, flores, frutos, raízes, rizomas, caules e sementes (SOUZA FILHO et al., 2011; SILVEIRA et al., 2014; MONTIEL et al., 2016).

Os aleloquímicos podem ser pertencentes a diversos grupos químicos, dentre eles destacam-se, os ácidos fenólicos, cumarinas, terpenóides, flavanoides, alcaloides e glicosídeos cianogênios (TEIXEIRA et al., 2014). Estes grupos químicos estão presentes nos processos fisiológicos das plantas, agindo como inibidores ou promotores de crescimento e germinação, que podem ser resultados das interferências em algumas atividades fisiológicas importantes para as plantas, como a divisão celular, permeabilidade das membranas, ativação das enzimas e produção de hormônios (TAIZ et al., 2013).

A importância dos processos que envolvem a alelopatia, consiste em uma prática que está em evidência em estudos científicos (ZENG, 2014), podendo ser vistos e empregados em análises prévias de bioensaios laboratoriais, utilizando plantas bioindicadoras como é o caso do pepino (Cucumis sativus L.), passando a ser um importante respaldo no estudo da sucessão ecológica de culturas agrícolas.

O feijão-guandu e o feijão-mungo, são importantes espécies da família das Fabaceae, sendo muito utilizadas para cultivos e produção em diferentes sistemas, desde o patronal até, principalmente, o familiar. Outros autores já apresentaram informações sobre o potencial alelopático de outras espécies dentro da família Fabaceae, como o Feijão-de-porco (FELITO et al., 2016; PEREIRA et al., 2018), Fedegoso (CÂNDIDO et 
al., 2010), Mulungu (CANTENARO et al., 2009; OLIVEIRA et al., 2012), e outras espécies arbóreas e nativas da família (OLIVEIRA et al., 2005; MARASCHIN-SILVA et al., 2006), ficando claro a importância de se obter maiores informações sobre o potencial alelopático das espécies utilizadas na presente pesquisa. Diante disso, objetivou-se com a pesquisa, avaliar o potencial alelopático de feijão-caupi (Vigna unguiculata L.) e feijãomungo-verde (Vigna radiata L.) na germinação e desenvolvimento inicial da cultura do pepino.

\section{MATERIAIS E MÉTODOS}

O presente trabalho foi desenvolvido entre os meses de maio a julho de 2019. As análises foram conduzidas em laboratório, visando obtenção de melhores respostas e maior controle dos bioensaios. Para a avaliação, foram obtidas sementes de duas espécies de feijoeiros utilizados na agricultura (feijão-caupi e feijão-mungo-verde), sendo obtidos do comercio agrícola da região. Após a obtenção, as sementes passaram por uma pré-limpeza, levadas dentro de sacos do tipo kraft para a estufa de circulação de ar forçado em temperatura de $40 \circ \mathrm{C}$ com variação de $\pm 2{ }^{\circ} \mathrm{C}$ em 72 horas, até obtenção de peso constante. A escolha da temperatura em torno de $40{ }^{\circ} \mathrm{C}$, ocorreu em virtude de ser uma temperatura usual na literatura, impossibilitando que as sementes pudessem perder algum composto secundário importante para a pesquisa por volatilização.

Posteriormente ao procedimento de secagem, as sementes foram moídas pelo moinho do tipo Willey visando a obtenção do pó homogêneo e confecção das respectivas concentrações dos extratos. Os tratamentos foram confeccionados utilizando o método de extração do pó homogêneo em água, posteriormente foi realizada a diluição em peso, dos pós das espécies, por volume de água (p/v). Inicialmente foi preparada a concentração matriz de 30\% (60g + $200 \mathrm{~mL}$ de água destilada), e em seguida foram retirando quantidades reconhecidas e inserido volumes iguais de água destilada com a finalidade de quebrar as respectivas concentrações para $15 \%$; 7,5\%; e $0 \%$ que era a testemunha composta apenas pela aplicação de água destilada.

O delineamento utilizado foi o inteiramente casualizado, em esquema fatorial $2 \times 4$. Os fatores foram constituídos por duas espécies de feijões (feijão-caupi e feijão-mungo-verde) e quatro concentrações do extrato dos grãos $(0 \%, 7,5 \%, 15 \%, 30 \%)$, e os tratamentos formados pela combinação dos fatores, constituídos por 4 repetições para cada tratamento. Para avaliação dos bioesnsaios utilizou o pepino (Cucumis sativus L.) cv. caipira como planta bioindicadora, onde previamente a implantação da pesquisa, foi empregado o teste padrão de germinação (TPG) para avaliação da sanidade das sementes, com o lote resultando em 98\% de germinação (BRASIL, 2009).

Para a confecção das unidades experimentais, foram distribuídas 25 sementes por repetição constituída de caixa acrílica do tipo gerbox $(11,0 \times 11,0 \times 3,5 \mathrm{~cm})$, e em seguida, foi inserido substrato composto por duas camadas de papel germitest (autoclavados 121 으 C de 15-20 minutos) e umedecidos 2,7 vezes sua massa seca pelas respectivas concentrações dos extratos (30\%; 15\%; $7,5 \%$; 0 ) seguindo recomendações de Brasil (2009). Após a disposição das sementes nas caixas gerbox, as mesmas foram acondicionadas em câmara de germinação tipo B.O.D. (Biochemical Oxygen Demand), com o tempo de 
exposição à luz de doze horas, sob temperatura constante de 25ํ․

As variáveis analisadas foram, índice de velocidade de germinação (IVG), porcentagem de germinação fisiológica (\%GF) e comprimento da parte aérea (CPA). Para o índice de velocidade de germinação adaptou-se a metodologia de Maguire (1986), sendo avaliadas diariamente as unidades experimentais e empregado o cálculo para o índice através da soma do número de sementes germinadas dividido pelo dia da observação, como expresso na equação 2. A germinação fisiológica foi avaliada no oitavo dia após a implantação do experimento, sendo considerada sementes germinadas, as que apresentavam protrusão de $2 \mathrm{~mm}$ da radícula após 7 dias de incubação em câmara de germinação (BRASIL, 2009), calculada de acordo com a equação 1. Para a variável comprimento da parte aérea, foi obtida pela medição do ponto de diferenciação do tecido da plântula (caulículo) até o ápice da parte aérea.

$$
\text { Equação 1: } \% \mathrm{GF}=\left(\frac{\mathrm{N}}{\mathrm{A}}\right) \times 100
$$

Em que: $\mathrm{N}$ : número de sementes germinadas;

Equação 2: $\mathrm{IVG}=\left(\frac{\mathrm{G} 1}{\mathrm{~N} 1}\right)+\left(\frac{\mathrm{G} 2}{\mathrm{~N} 2}\right)+\left(\frac{\mathrm{G} 3}{\mathrm{~N} 3}\right)+\cdots\left(\frac{\mathrm{Gn}}{\mathrm{Nn}}\right)$ A: número total de sementes.

$\mathrm{G} 1, \mathrm{G} 2, \mathrm{G} 3, \ldots, \mathrm{Gn}=$ número de sementes germinadas no dia da observação. $\mathrm{N} 1, \mathrm{~N} 2, \mathrm{~N} 3, \ldots \mathrm{Nn}$ = número de dias após incubação. As médias dos tratamentos foram submetidas à análise de variância (ANOVA) pelo teste F. Os efeitos das espécies de feijões quando significativos foram comparados pelo teste Tukey a $5 \%$ de probabilidade. Enquanto para as diferentes concentrações dos extratos, realizou-se o estudo de regressão polinomial. A análise estatística foi realizada utilizando-se o software Sisvar (FERREIRA, 2011) e para o desenvolvimento dos gráficos utilizando o software Sigma Plot.

\section{RESULTADOS E DISCUSSÃO}

Foram observadas diferenças significativas para todas as variáveis em estudo sob ação dos fatores isolados (espécies de feijões e concentração dos extratos). Enquanto para interação entre os fatores, foram observadas diferenças significativas para todas as variáveis exceto para porcentagem germinação, pelo teste F a 5\% de significância (Tabela 1).

De uma maneira geral analisando os dados, todas as variáveis se enquadraram em um bom coeficiente de variação, demonstrando assim que os dados em estudo apresentam dentro dos parâmetros normais, padrões aceitáveis de variação dos dados em relação às médias das variáveis (PIMENTEL-GOMES, 1985). Alguns parâmetros na curva resposta das variáveis estudadas, apresentaram significância em pelo menos um dos modelos de regressão polinomial, independente da natureza (espécie) do extrato, o que facilitou o entendimento dentro dos respectivos desdobramentos.

A porcentagem de germinação sofreu influência dos extratos das espécies e das concentrações. Diante dos resultados, foi observado que houve decréscimos para a germinação de sementes de pepino, independente das espécies de feijões em estudo. Esses resultados são confirmados ao avaliar o teste padrão de germinação fisiológica, conduzido antes da implantação do experimento para avaliação das condições das 
sementes utilizadas (onde as sementes apresentaram 98\% de germinação), com isso, quando comparado os extratos independente das concentrações, observa-se decréscimos de 8,16\% e 15,30\% para feijão-mungo e feijão-caupi, respectivamente (Tabela 2).

Tabela 1: Quadrados médios das variáveis Porcentagem de Germinação (\%GERM), Índice de Velocidade de Germinação (IVG), Comprimento da Parte Aérea (COMPA) de plântulas de pepino submetido a diferentes extratos e concentrações de feijão-mungo-verde e feijão-caupi.

\begin{tabular}{|c|c|c|c|c|c|c|}
\hline \multirow[t]{3}{*}{ FV } & \multicolumn{6}{|c|}{ Quadrados médios } \\
\hline & \multicolumn{6}{|c|}{ Variáveis } \\
\hline & \multicolumn{2}{|c|}{$\%$ \%ERM } & \multicolumn{2}{|l|}{ IVG } & \multicolumn{2}{|l|}{$\mathrm{CPA}$} \\
\hline Espécie & 392.00 & ${ }^{*}$ & 33.722 & ${ }^{*}$ & 3.645 & * \\
\hline Concentração & 876.00 & ${ }^{*}$ & 67.463 & ${ }^{*}$ & 87.460 & * \\
\hline Esp*Concen & 33.33 & ns & 3.875 & ${ }^{*}$ & 3.919 & * \\
\hline Erro & 13.66 & & 0.606 & & 0.434 & \\
\hline \multirow[t]{2}{*}{ CV (\%) } & 4.27 & & 3.76 & & 21.60 & \\
\hline & & \multicolumn{5}{|c|}{ Feijão-mungo-verde } \\
\hline Reg Lin & 0.00 & ${ }^{*}$ & 0.00 & ${ }^{*}$ & 0.00 & * \\
\hline \multirow[t]{2}{*}{ Reg Quad } & 0,01 & ${ }^{*}$ & 0.41 & $\mathrm{~ns}$ & 0.39 & $n$ \\
\hline & & \multicolumn{5}{|c|}{ Feijão-caupi } \\
\hline Reg Lin & 0.00 & ${ }^{*}$ & 0.00 & ${ }^{*}$ & 0.00 & * \\
\hline Reg Quad & 0.01 & ${ }^{*}$ & 0.04 & ${ }^{*}$ & 0.00 & * \\
\hline
\end{tabular}

${ }^{*}$ significativo; ${ }^{\text {ns }}$ não significativo pelo teste de F a 5\% de significância.

Dessa forma, é notável que houve alguma interferência alelopática independente dos extratos testados, mesmo que pouco pronunciada. Ademais, o extrato a partir do feijão-caupi foi o que apresentou os maiores prejuízos para esta variável, o que demonstra ter algum composto secundário mais prejudicial para o desenvolvimento germinativo quando comparado com o extrato de feijão-mungo. Alguns autores como Carvalho et al. (2014), Bulegon et al. (2015), Saraiva et al. (2016) e Novais et al. (2017), já demonstraram o potencial alelopático de outras espécies da família Fabaceae em plantas bioindicadoras, onde os resultados apresentados corroboraram com os observados na presente pesquisa, pois a presença do extrato aquoso atuou de maneira contrária ao incremento da variável germinação fisiológicas das sementes.

Nos processos germinativos, uma de suas fases mais importantes, está o processo de embebição das sementes, nela as sementes fazem a absorção de água presente no meio para iniciar os processos fisiológicos como ruptura do tegumento e protusão da radícula. Diante disso, neste processo de embebição para os decréscimos observados para a variável, as sementes absorveram alguma substância capaz de interferir diretamente ou até mesmo retardando a multiplicação e o crescimento das células do vegetal, e o reflexo disso, são as desordens fisiológicas resultando em queda ou até mesmo inibição de germinação (GONZALES et al., 2002; SILVA et al., 2018).

Entretanto vale observar, que a ação dos extratos independente das diferenças significativas, foram poucos pronunciados para a germinação das sementes de pepino. Esses resultados podem ser explicados, pois os processos germinativos são os menos influenciados pelas condições alelopáticas (FERREIRA et al., 2000; ROSADO et al., 2009). Visto que, na germinação as sementes apresentam substâncias de reservas necessárias para independência de fatores externos no meio, os reflexos mais acentuados são observados na velocidade da germinação no campo e desenvolvimento inicial de plântulas, por isso as avaliações necessitam ser diárias (ROSADO et al., 2009), afim de avaliar o efeito da germinação no tempo. 
Tabela 2: Comparativo de média para a variável porcentagem de germinação de sementes (\%GER) de pepino submetido a extrato aquoso de diferentes espécies e concentrações de feijão.

\begin{tabular}{|c|c|c|c|c|c|}
\hline \multirow[t]{2}{*}{ Espécie de feijão } & \multirow{2}{*}{\multicolumn{2}{|c|}{$\begin{array}{l}\text { Germinação } \\
\text { Média }\end{array}$}} & \multirow[t]{2}{*}{ Concentração dos extratos (\%) } & \multicolumn{2}{|c|}{ Germinação } \\
\hline & & & & Média & \\
\hline \multirow[t]{2}{*}{ Feijão-mungo } & \multirow[t]{2}{*}{90.00} & \multirow[t]{2}{*}{ A } & 0 & 24.62 & $\mathrm{~A}$ \\
\hline & & & 7,5 & 22.75 & B \\
\hline \multirow[t]{2}{*}{ Feijão-caupi } & \multirow[t]{2}{*}{83.00} & \multirow[t]{2}{*}{ B } & 15 & 20.50 & $\mathrm{C}$ \\
\hline & & & 30 & 18.62 & $\mathrm{D}$ \\
\hline
\end{tabular}

Médias seguidas de mesma letra maiúscula na coluna não diferem pelo teste de Tukey a 5\% de significância.

A influência das concentrações dos extratos na germinação de sementes, pode ser observada na Figura 1. Conforme houve o aumento das concentrações dos extratos, independente da espécie em estudo, houve tendência a diminuição da germinação das sementes de pepino. O modelo de regressão ajustado aos dados foi o quadrático, e a escolha do modelo ajustado, deu-se em virtude da busca de alguma tentativa de recuperação por parte das sementes no processo germinativo, apresentando um coeficiente de determinação $\left(R^{2}=99.98 \%\right)$ com apenas $0.02 \%$ dos dados não podendo ser explicado pelo modelo, o que nos apresenta bons respaldos dentro do modelo escolhido para o ajuste.

Em detrimento a isso, uma das explicações pela germinação ter sofrido decréscimo conforme ocorreu o aumento das concentrações, está relacionada a quantidade de compostos secundários que estão sendo prontamente disponibilizados para as sementes, isso por que, se compararmos o aumento na concentração do extrato entre a menor $(7,5 \%)$ e a maior $(30 \%)$, nota-se que há um aumento de $300 \%$ na quantidade de compostos prontamente disponibilizados para as sementes. Esses resultados corroboram com pesquisas como a de Carvalho et al. (2014), que avaliando os extratos de adubos verdes (feijão-de-porco, feijão-de-porco + aveia preta e feijão-de-porco + sorgo) em bioensaios laboratoriais, observaram redução significativa na germinação das sementes partir de concentrações de 10\% e Araújo et al. (2014) que avaliando o extrato aquoso de crotalária ocroleuca (família similar a das espécies em estudo) em sementes de milho, foram observadas reduções significativas na germinação das sementes logo nas concentrações de $25 \%$.

Felito et al. (2016), realizaram testes do potencial alelopático do feijão-de-porco (Canavalia ensiformes) sobre o desenvolvimento de alface (Lactuca sativa L.), os mesmos notaram que nas concentrações de $15 \%$ e $30 \%$ ocorreu inibição na germinação das sementes de alface. Esses resultados reforçam que espécies da família Fabaceae são objetos de importante estudo sobre o potencial alelopático para uso em manejos ecológicos.

Além disso, esse indicativo do aumento da concentração na influência direta sobre a germinação das sementes, também é explicada por outros autores. Kremer et al. (2016), apontam que as respostas de maiores doses nos efeitos alelopáticos de culturas, está relacionado diretamente com o aumento da concentração do composto secundário disponibilizado. Dessa maneira, quanto maior a concentração e o tempo de disponibilização do composto para as sementes, maior o potencial delas se hidratarem nos processos de embebição, e por consequência, maior será o potencial de retardar a multiplicação ou crescimento das células, bem como a germinação (RITTER, 2014), confirmando o observado na presente pesquisa. 


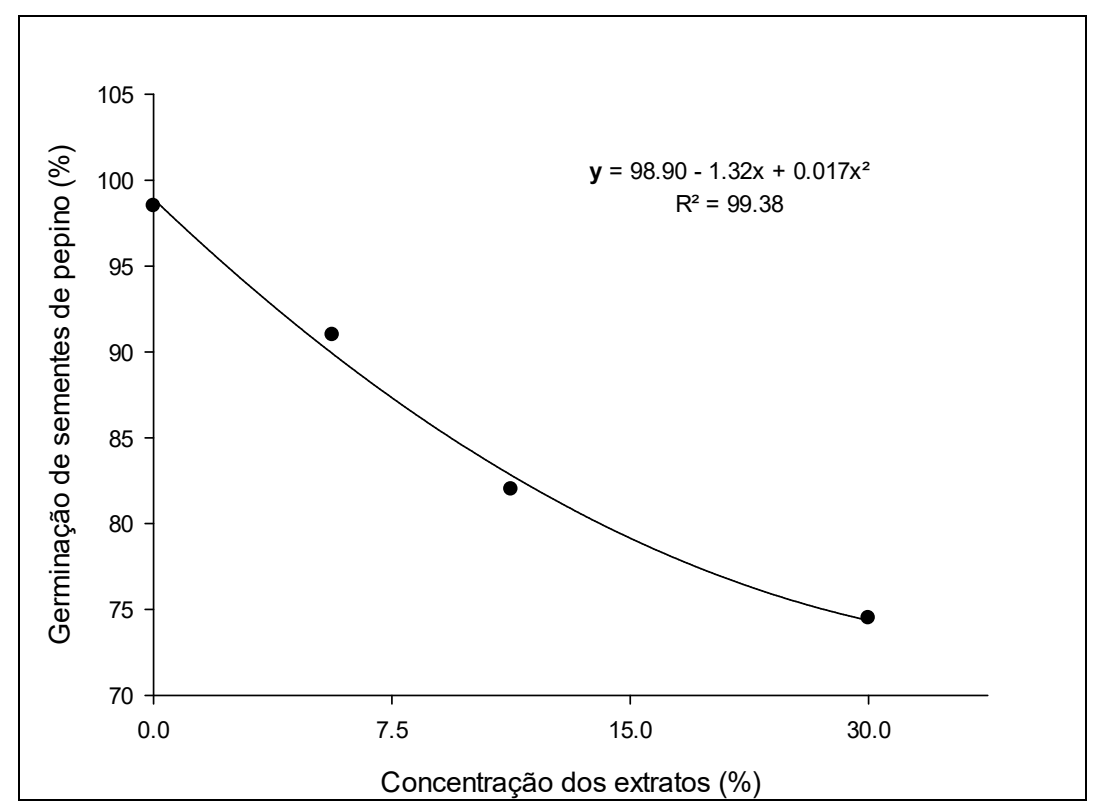

Figura 1: Regressão polinomial para o fator concentração dos extratos de feijão-mungo e feijão-caupi na germinação de sementes de pepino (Cucumis sativus L.).

A velocidade de germinação de sementes (IVG), foi influenciada pelos efeitos dos fatores estudados. De maneira similar a germinação de sementes, o feijão-caupi apresentou os maiores efeitos quando comparado com o feijão-mungo, independente da dose estudada (Tabela 3). As diferenças dos prejuízos no decréscimo para a velocidade de germinação observado entre o feijão-caupi e o feijão-mungo foram de 5.8\% não diferindo significativamente, $8.5 \%, 8 \%$ e $20.70 \%$ nas concentrações de $0,7,5,15$ e $30 \%$, respectivamente.

Tabela 3: Análise de desdobramento dos fatores espécies $x$ concentrações para variável Índice de Velocidade de Germinação de sementes de pepino submetido a concentrações e extrato aquoso de diferentes espécies de feijão.

\begin{tabular}{|c|c|c|c|c|c|c|c|c|}
\hline & Índice & cida & germi & & & & & \\
\hline \multirow[t]{2}{*}{ Espécie de feijão } & \multicolumn{8}{|c|}{ Concentrações } \\
\hline & 0 & & 7.5 & & 15 & & 30 & \\
\hline F. mungo & 24.09 & $\mathrm{Aa}$ & 23.17 & $\mathrm{Aa}$ & 20.64 & $A b$ & 19.08 & $A c$ \\
\hline F. caupi & 23.45 & $\mathrm{Aa}$ & 21.19 & $\mathrm{Bb}$ & 19.00 & $\mathrm{Bc}$ & 15.13 & $\mathrm{Bd}$ \\
\hline
\end{tabular}

Médias seguidas de mesma letra maiúscula na coluna e minúscula na linha não diferem pelo teste de Tukey a $5 \%$ de significância.

Esses efeitos redutivos na velocidade de germinação, novamente é explicado pelo efeito diferencial na quantidade compostos nos extratos, que fazem com que nos primeiros dias não seja observado nitidamente esta diferença, porém seus efeitos prejudiciais são vistos dentro de uma distribuição temporal, como visto no IVG. Autores como Bulegon et al. (2015), apontam que o índice de velocidade de germinação, tem mostrado ser um importante e sensível parâmetro influenciado pelas condições alelopáticas em estudos, condições essas reforçada por outros trabalhos como o de Borella et al. (2010), que apresentam que a velocidade de germinação, apresenta sempre um bom indicativo para as avaliações de compostos secundários inibindo ou estimulando os processos de velocidade de germinação.

O efeito alelopático no IVG, é um parâmetro preocupante no campo, pois pode influenciar diretamente a tomada de decisão e nos custos de produção, pelo fato de alterar condições relacionadas a uniformidade na emergência de plântulas nos estandes. Com isso, esses resultados da velocidade de germinação induzidos pelos extratos de feijão-caupi e feijão-mungo eram esperadas, pois Ferreira e Áquila 
(2000) apresentam que os efeitos alelopáticos costumam aparecer de maneira mais severa no IVG do que na germinação final de sementes.

A análise de regressão polinomial, demonstra os efeitos de decréscimos na velocidade de germinação, sob a ação de cada uma das espécies de feijão em estudo (feijão-caupi linha contínua e feijãomungo tracejada). Ambos os extratos apresentaram ajuste ao modelo linear apresentando tendência decrescente, demonstrando que conforme foi aumentando a concentração, houve nítida tendência de decréscimo da velocidade de germinação das sementes de pepino (Figura 2).

Com isso, conforme foi aumentando as concentrações $(0,7,5,15$ e 30\%), houve decréscimos que flutuaram em torno de 9,$6 ; 18,97 ; 35,47 \%$ para o feijão-caupi e 3,8; 14,32 e 20,79\% para o feijão-mungo em comparação com suas testemunhas apenas com água destilada, respectivamente. Dessa forma, outros trabalhos demonstram a sensibilidade na distribuição da germinação no tempo sob a ação algum tipo de composto alelopático, pois de acordo com Pereira et al. (2018), avaliando o aumento da concentração do extrato aquoso de feijão-de-porco (Canavalia ensiformis L.) em espécies indicadoras, observou efeitos de decréscimos em várias espécies receptoras como Lactuca sativa (alface), Digitaria insularis (Capim amargoso), Emilia coccinea (Falsa-serralha) e Portulaca oleracea (Beldroega) utilizadas para testes nos bioensaios.

Outros resultados comprobatórios são vistos na literatura, confirmando os resultados observados na pesquisa sobre a interferência na velocidade de germinação. Onde Silva et al. (2010), avaliaram o índice de velocidade de germinação de sementes de alface e couve submetidos aos extratos de Anadenanthera macrocarpa (Fabaceae) e Astronium graveolens (Anacardiaceae), e os mesmos verificaram interferência direta na velocidade de germinação, fazendo com que, as sementes reduzissem o seu vigor (capacidade de germinar e desenvolver uma planta normal em um curto espaço de tempo) pela ação dos extratos.

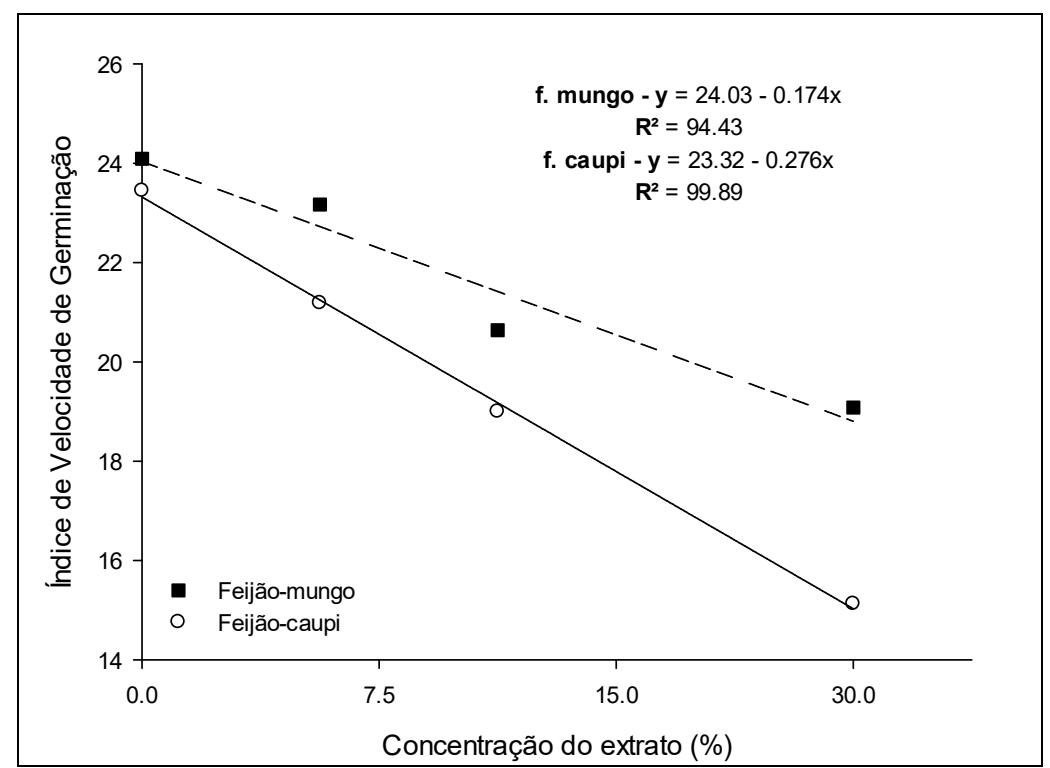

Figura 2: Regressão polinomial para a interação do fator espécie x concentração dos extratos de feijão-mungo e feijãocaupi no índice de velocidade de germinação (IVG) de sementes de pepino (Cucumis sativus L.).

Para tanto, essa influência com o aumento das concentrações dos extratos do feijão-caupi e feijãomugo na presente pesquisa, é um problema que no campo precisa ser evitado. Atrasos na germinação em 
culturas comerciais não são desejadas, pois além das sementes estarem expostas à os ataques de pragas e doenças, formam um estande desuniforme (CASTAGNARA et al., 2012) acarretando em prejuízos ao produtor.

Algumas das explicações sobre o real efeito do extrato de algumas leguminosas na germinação e IVG de sementes que foi objetivo do presente estudo, é observado em pesquisas como o de Marinov-Serafimov (2010), onde demonstram que a sensibilidade de espécies receptoras, como é o caso do pepino, ocorrem em decorrência de diferentes mecanismos de absorção, translocação e do sítio de ativação do composto alelopático e isso pode ser alterado conforme ocorre o aumento da concentração do extrato, influência do ambiente, além do estágio de desenvolvimento da planta (TAIZ et al., 2013).

O comprimento da parte aérea de plântula de pepino, nitidamente foi comprometido pela ação dos extratos (Tabela 4). Novamente o extrato proveniente do feijão-caupi apresentou os efeitos mais prejudiciais quando comparado ao feijão-mugo em todas as concentrações exceto a $30 \%$, que independente da espécie, as desordens foram tão severas que levaram ao não desenvolvimento da parte aérea, com 100\% de mortalidade de plântula.

A variação dos extratos quando comparados, podem ser observadas pois o reflexo no decréscimo do comprimento da parte aérea foram de 39,93 e 100\% para as doses de 7,5 e 15\% comparando o feijão-caupi para o feijão-mungo. Esses valores apresentados reforçam que os efeitos alelopáticos são observados mais severamente no desenvolvimento inicial de plântulas quando comparado com a germinação de sementes (FERREIRA et al., 2000).

Tabela 4: Análise de desdobramento dos fatores espécies x concentrações para variável Comprimento da Parte Aérea de plântulas de pepino submetido a concentrações e extrato aquoso de diferentes espécies de feijão.

\begin{tabular}{|l|l|l|l|l|l|l|l|l|}
\hline \multirow{2}{*}{ Espécie de feijão } & \multicolumn{6}{l|}{ Comprimento da Parte Aérea } \\
& \multicolumn{2}{l}{ Concentrações } \\
\cline { 2 - 11 } & 0 & 7.5 & & 15 & & 30 & \\
\hline F. mungo & 6.50 & $\mathrm{Aa}$ & 5.81 & $\mathrm{Aa}$ & 1.25 & $\mathrm{Ab}$ & 0.00 & $\mathrm{Ab}$ \\
\hline F. caupi & 7.37 & $\mathrm{Aa}$ & 3.49 & $\mathrm{Bb}$ & 0.00 & $\mathrm{Bc}$ & 0.00 & $\mathrm{Ac}$ \\
\hline
\end{tabular}

Médias seguidas de mesma letra maiúscula na coluna e minúscula na linha não diferem pelo teste de Tukey a $5 \%$ de significância.

Para o efeito de concentração dos extratos dentro de cada nível de espécie, novamente as doses atuaram diretamente no decréscimo do comprimento da parte aérea das plântulas de pepino (Figura 3). Analisando o feijão-mungo, foi observado ajuste linear na curva de regressão explicando aproximadamente 85.99\% dos dados obtidos pelo coeficiente de determinação $\left(R^{2}\right)$, sendo assim, ao se comparar o aumento da concentração do extrato da espécie, os decréscimos aconteceram na ordem de 10,6; 80,7 e 100\% quando comparado com a testemunha composta apenas por água destilada para as concentrações de 7,5; 15 e 30\%, respectivamente. Demonstrando que, logo, na concentração intermediária 15\%, apenas 19,3\% das plântulas apresentavam alguma parte aérea desenvolvida, enquanto para a maior concentração, as sementes chegaram a germinar fisiologicamente, mas não tiveram o desenvolvimento da parte aérea.

Para o feijão-caupi, os efeitos prejudiciais puderam ser observados logo na primeira concentração de $7,5 \%$ ocasionando redução de $52,6 \%$, sendo essa concentração 5 vezes mais prejudicial quando comparada 
a mesma do feijão-mungo. Enquanto que, o não desenvolvimento da parte aérea (100\%) foi observada logo nas doses de 15 e 30\%, respectivamente. Esses resultados corroboram com outros já relatados na literatura, utilizando espécies da mesma família, pois Pereira et al. (2018) observou que uma das variáveis mais prejudicadas foi o comprimento de plântulas utilizando extrato de feijão-de-porco, isso mostrou que conformo houve o aumento na concentração do extrato, maiores foram os decréscimos e os prejuízos para essa variável em plantas bioindicadoras.

A alelopatia consiste na liberação de metabolitos secundários, no qual inibem ou retardam principalmente o desenvolvimento de plântulas, com isso, a utilização de altas concentrações de extratos pode estar relacionada a maior concentração de substâncias tóxicas presente nos líquidos solúveis do vegetal (SILVA et al., 2016), confirmando que os efeitos alelopáticos são dependentes da concentração desses extratos.

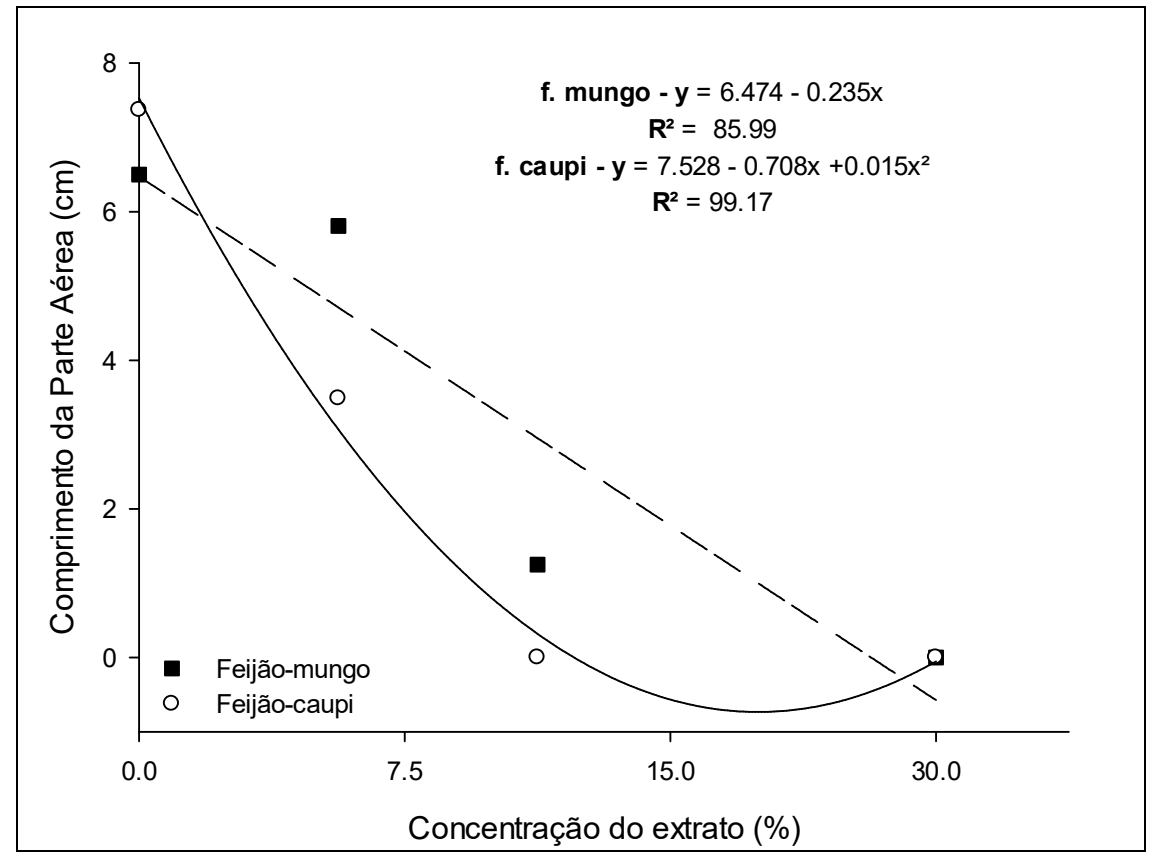

Figura 3: Regressão polinomial para a interação do fator espécie $x$ concentração dos extratos de feijão-mungo e feijãocaupi no comprimento da parte aérea (CPA) de plântulas de pepino (Cucumis sativus L.).

Outras pesquisas também observaram prejuízos alelopáticos com outras espécies da família Fabaceae. Simonneti et al. (2019), avaliando o potencial alelopático de extrato de sementes de Crotalaria uchroleuca, observou decréscimos significativos, conforme houve o aumento das concentrações ocorreu prejuízos severos no desenvolvimento inicial de plântulas, sendo a variável mais afetada foi o comprimento de plântulas. Essas desordens ocasionadas pelos extratos de espécies da família Fabaceae (feijão-mungo e feijão-caupi), provavelmente é estimulado por algum composto secundário já presente nas espécies da família sobre quantidades diferentes em cada espécie, pois Pires et al. (2017), avaliando doses do extrato aquoso de Crotalária juncea observou um acréscimo no número de plântulas anormais com aplicação dos tratamentos.

Em estudos buscando avaliar o potencial alelopático de feijão-do-campo (Macroptilium lathyroides), Silva et al. (2018), observou influência direta no desenvolvimento da parte aérea ocorrendo redução de 60\% logo na concentração de $10 \%$ do extrato da folha, isso por que, espécies da mesma família podem apresentar 
similaridade na presença de compostos secundários em seu metabolismo, sejam eles na folha, fruto ou sementes. Dessa maneira, esses efeitos deletérios observado nas variáveis da presente pesquisa, principalmente sob influência do extrato do feijão-caupi, pode ser explicado por Souza et al. (2013), que em sua análise histoquímica em espécies de feijão-de-pombinha (Fabeceae) encontrou vários compostos secundários, como b-sitosterol, estigmasterol, estigmast-4-en-6b-ol-3-ona, estigmast-4,22-dien-6b-ol-3ona, (R)-des-O-metil-lasiodiplodina, lupinalbina e genisteína, que podem ser encontrados em outras espécies na família e serem um dos precursores de possíveis inibições no desenvolvimento de algumas bactérias, bem como em espécies de vegetais como observado na presente pesquisa.

Para tanto, estudos com as espécies da família Fabaceae precisam ser implementados, afim de buscar alternativas naturais para o manejo alternativo dos agroecossistemas. Em detrimento a isso, poucos são os trabalhos que buscam elucidar as respostas de feijão-caupi e feijão-mungo-verde na literatura, dessa forma, diante dos resultados preliminares da pesquisa, essas espécies analisadas em estudo apresentam potencial uso em programas de avaliação do potencial alelopático para uso em manejo alternativo.

\section{CONCLUSÕES}

Diante dos resultados da pesquisa, podemos concluir que as espécies apresentam potencial alelopático sobre a germinação e desenvolvimento inicial da cultura do pepino, com destaque para o feijãocaupi (Vigna unguiculata) que apresentou os melhores potenciais inibitórios de desenvolvimento e o maior potencial alelopático quando comparado com o feijão-mungo (Vigna radiata), contribuindo assim para a busca de novas alternativas para o manejo ecológico dos sistemas agrícolas.

\section{REFERÊNCIAS}

ARAÚJO, E. O.; SANTANA, C. N.; ESPÍRITO SANTO, C. L.. Potencial alelopático de extratos vegetais de Crotalaria juncea sobre a germinação de milho e feijão. Revista Brasileira de Agroecologia, Dois vizinhos, v.6, n.1, p.108116, 2011.

BORELLA, J.; TUR, C. M.; PASTORINI, L. H.. Alelopatia de extratos aquosos de Duranta repens sobre a germinação e o crescimento inicial de Lactuca sativa e Lycopersicum esculentum. Biotemas, Florianópolis, v.23, n.2, p.13-22, 2010. DOI: http://doi.org/10.5007/21757925.2010v23n2p13

BRASIL. Ministério da Agricultura, Pecuária e Abastecimento. Regras para Análises de Sementes. Brasília: MAPA, 2009.

BULEGON, L. G.; MEINERZ, C. C.; CASTAGNARA, D. D.; BATTISTUS, A. G.; GUIMARÃES, V. F.; NERES, M. A.. Alelopatia de Espécies Forrageiras Sobre a Germinação e Atividade de Peroxidase em Alface. Scientia Agraria Paranaensis, Marechal Cândido Rondon, v.14, n.2, p.94-99, 2015. DOI: http://dx.doi.org/10.18188/sap.v14i2.8385

CÂNDIDO, A. C. S.; SCHMIDT, V.; LAURA, V. A.; FACCENDA, O.; HESS, S. C.; SIMIONATTO, E.; PERES, M. T. L. P.. Potencial alelopático da parte aérea de Senna occidentalis (L.) Link (Fabaceae, Caesalpinioideae): bioensaios em laboratório.
Acta Botânica Brasílica, São Paulo, v.24, n.1, p.235-242, 2010. DOI: http://doi.org/10.1590/S0102$\underline{33062010000100025}$

CARVALHO, W. P.; CARVALHO, G. J.; ABBADE NETO, D. O.; TEIXEIRA, L. G. V.. Alelopatia de extratos de adubos verdes sobre a germinação e crescimento inicial de alface. Bioscience Journal, Uberlândia, v.30, n.1, p.1-11, 2014.

CASTAGNARA, D. D.; MEINERZ, C. C.; MULLER, S. F.; SCHMIDT, M. A. H.; PORTZ, T. M.; OBICI, L. V.; GUIMARÃES, V. F.. Potencia alelopático de aveia, feijão guandu, azevém e braquiária na germinação de sementes e atividade enzimática do pepino. Ensaios e Ciência: Ciências Biológicas, Agrárias e da Saúde, Londrina, v.16, n.2, p.31- 42, 2012.

CANTENARO, C.; CORRÊA, L. G. P.; KARAS, M. J.; VIRTUOSO, S.; DIAS, J. E. G.; MIGUEL, O. G.; MIGUEL, M. D.. Contribuição ao estudo alelopático de Erythrina velutina Willd., Fabaceae. Revista Brasileira Farmacognosia, Curitiba, v.19, n.1, p.304308, 2009. DOI: http://doi.org/10.1590/S0102$\underline{695 \times 2009000200021}$

CREMONEZ, F. E.; CREMONEZ, P. A.; CAMARGO, M. P.; FEIDEN, A.. Principais plantas com potencial alelopático encontradas nos sistemas agrícolas brasileiros. Acta Iguazu, Cascavel, v.2, p.70-88, 2013. 
FELITO, R. A.; GÖTTERT, V.; ORTIS, R. C.; GONÇALVES, G. S.; YAMASHITA, O. M.. Potencial alelopático do feijão de porco (Canavalia ensiformes) no desenvolvimento de alface (Lactuca sativa L.) sob diversas concentrações. Cadernos de Agroecologia, Vitória, v.10, n.3, 2016.

FERREIRA, A. G.; AQUILA, M. E. A.. Alelopatia: uma área emergente da ecofisiologia. Revista Brasileira de Fisiologia Vegetal, Viçosa, v.12, p.175-204, 2000.

FERREIRA, D. F.. Sisvar: a computer statistical analysis system. Ciência e Agrotecnologia, Lavras, v.35, n.6, p.10391042, 2011. DOI: http://doi.org/10.1590/S1413$\underline{70542011000600001}$

GONZALEZ, H. R.; MEDEROS, M. D.; SOSA, I. H.. Efectos alelopáticos de restos de diferentes espécies de plantas medicinales sobre la albahaca (Ocimum basilicum L.) em condiciones de laboratório. Revista Cubana de Plantas Medicinales, Habana, v.7, n.2, p.67-72, 2002.

KREMER, T. C. B.; YAMASHITA, O. M.; FELITO, R. A.; FERREIRA, A. C. T.; ARAÚJO, C. F.. Atividade Alelopática de Extrato Aquoso de Croton Glandulosus L. Na Germinação e no Desenvolvimento Inicial de Alface. Revista da

Universidade Vale do Rio Verde, Três Corações, v.14, n.1, p.890-898, 2016. DOI:

http://dx.doi.org/10.5892/ruvrd.v14i1.2628

MONTIEL, C. B.; LIMA, C. T.; SIMONETTI, A. P. M. M.. Extrato de frutos de crambe sobre a germinação e desenvolvimento inicial de plântulas de trigo e azevém. Acta Tecnológica, São Luiz, v.11, n.1, p.57-65, 2016.

MAGUIRE, J. D.. Speeds of germination-aid selection and evaluation for seedling emergence and vigor. Crop Science, Madison, v.2, p.176-177, 1962.

MARASCHIN-SILVA, F.; AQUILA, M. E. A.. Potencial alelopático de espécies nativas na germinação e crescimento inicial de Lactuca sativa L. (Asteraceae). Acta Botânica Brasilica, São Paulo, v.20 n.1, p.61-69, 2006. DOI: http://doi.org/10.1590/S0102-33062006000100007

MARINOV-SERAFIMOV, P.. Determination of allelopathic effect of some invasive weed species on germination and initial development of grain legume crops. Pesticides \& Phytomedicine, v.25, n.1, p.251-259, 2010.

MAULI, M. M.. Alelopatia de Leucena sobre soja e plantas invasoras. Semina: Ciências Agrárias, Londrina, v.30, n.1, p.55-62, 2009. DOI: http://doi.org/10.5433/1679$\underline{0359.2009 v 30 n 1 p 55}$

NOVAIS, D. B.; SOUTO, J. S.; SOUTO, P. C.; LEONARDO, F. A. P.; BARROSO, R. F.. Efeito alelopático dos extratos aquosos de folhas e raízes de Luetzelburgia auriculata $\mathrm{L}$. sobre a germinação da alface. ACSA, Patos, v.13, n.3, p.247-254, 2017. DOI: http://dx.doi.org/10.30969/acsa.v13i3.896

OLIVEIRA, A. K.; COELHO, M.F B.; MAIA, S. S. S.; DIÓGENES, F. E. P.; MEDEIROS FILHO, S.. Alelopatia de extratos de diferentes órgãos de mulungu na germinação de alface. Horticultura Brasileira, Recife, v.30, n.3, p.480-483, 2012. DOI: http://doi.org/10.1590/S0102-05362012000300020
OLIVEIRA, M.N.S.; MERCADANTE-SIMÕES, M.O.; RIBEIRO, L.M.; LOPES, P.S.N.; GUSMÃO, E.; DIAS, B.A.S. Efeitos alelopáticos de seis espécies arbóreas da família Fabaceae. Unimonte Científica, Montes Claros, v.7, n.2, p.121-128, 2005.

PEREIRA, J. C.; PAULINO, C. L. A.; GRANJA, B. S.; SANTANA, A. E. G.; ENDRES, L.; SOUZA, R. C.. Potencial alelopático e identificação dos metabólitos secundários em extratos de Canavalia ensiformis L. Revista Ceres, Viçosa, v.65, n.3, p.243-252, 2018. DOI: http://doi.org/10.1590/0034737×201865030004

PIMENTEL-GOMES, F.. Curso de Estatística Experimental. Piracicaba: USP, 1985.

PIRES, W.; MORAIS, D. C. O.; WERLANG, T.; RADUNZ, A. L.; TIRONI, S. P.. Efeito Alelopático de Extratos de Crotalaria Juncea na Germinação e Desenvolvimento Inicial de Cevada. Agrarian Academy, Goiânia, v.4, n.8, p.120-129, 2017. DOI: http://doi.org/10.18677/Agrarian Academy 2017b13

RITTER, M. C.; YAMASHITA, O. M.; CARVALHO, M. A. C.. Efeito de extrato aquoso e metanólico de nim (Azadiracta indica) sobre a germinação de alface. Multitemas, Campo Grande, v.1, n.46, p.9-21, 2014.

ROSADO, L. D. S.; RODRIGUES, H. C. A.; PINTO, J. E.B. P.; CUSTÓDIO, T. N.; PINTO, L. B. B.; BERTOLUCCI, S. K. V.. Alelopatia do extrato aquoso e do óleo essencial de folhas do manjericão "Maria Bonita" na germinação de alface, tomate e melissa. Revista Brasileira Plantas Medicinais, Botucatu, v.11, n.4, p.422-428, 2009. DOI: http://doi.org/10.1590/S1516-05722009000400010

SANTOS, C. C.; SILVA, L. G.; SILVA, G. C.; FERRAZ JUNIOR, A. S. L.. Alelopatia entre leguminosas arbóreas e feijão-caupi. Scientia Agraria, Curitiba, v.11, n.3, p.187-192, 2010. DOI: http://dx.doi.org/10.5380/rsa.v11i3.17512

SARAIVA, T. S.. Efeitos alelopáticos de espécies do gênero Arachis: uma revisão da literatura. Revista Agroveterinária, Negócios e Tecnologias, Coromandel, v.1, n.1, p.8-27, 2016.

SILVA, R. M. G.; SARAIVA, T. S.; SILVA, R. B.; GONÇALVES, L. A.; PEREIRA, L.. Potencial alelopático de extrato etanólico de Anadenanthera macrocarpa e Astronium graveolens. Bioscience Journal, Uberlândia, v.26, n.4, p.632-637, 2010.

SILVA, T. A.; DELIAS, D.; PEDÓ, T.; ABREU, E. S.; VILLELA, F. A.; AUMONDE, T. Z.. Fitotoxicidade do extrato de Conyza bonariensis (L.) Cronquist no desempenho fisiológico de sementes e plântulas de alface. Iheringia Série Botânica, Porto Alegre, v.71, n.3, p.213-221, 2016.

SILVA, M. S. A.; YAMASHITA, O. M.; ROSSI, A. A. B.; KARSBURG, I. V.; CONCENÇO, G.; FELITO, R. A.. Potencial alelopático do extrato aquoso das folhas e raízes frescas de Macroptilium lathyroides na germinação e no desenvolvimento inicial de alface. Revista de Ciências Agroambientais, Alta Floresta, v.16, n.1, p.89-95, 2018. DOI: http://doi.org/10.5327/Z1677-606220181612

SILVEIRA, B. D.; HOSOKAWA, R. T.; NOGUEIRA, A. C.; WEBER, V. P.. Atividade Alelopática de Araucaria angustifolia (Bertol.) Kuntze na Germinação e Crescimento Inicial de 
Lactuca sativa L. Ciência Florestal, Santa Maria, v.24 n.1, p.79-85, 2014. DOI: http://doi.org/10.5902/1980509813325

SIMONETTI, A. A. M. M.; PERES, D. M.; CANZI, G. M.; SOUZA, G. B. P.; EFFTING, P. B.; MOREIRA, C. B...Alelopatia da Crotalária Ochroleuca Sobre a Cultura da Soja. Revista Técnico-Científica do CREA, p.1-13, 2019.

SOUSA, L. M.; GOIS, R. W. S.; LEMOS, T. L. G.; ARRIAGA, A. M. C.; ANDRADE NETO, M.; SANTIAGO, G. M. P.; BRAZ FILHO, R.; COSTA, JOSÉ G. M.; RODRIGUES, F. F. G.. Constituintes químicos e avaliação da atividade antibacteriana de Macroptilium lathyroides (L.) Urb. (Fabaceae). Química Nova, São Paulo, v.36, n.9, p.1370-1374, 2013. DOI: http://doi.org/10.1590/S0100-40422013000900016

SOUZA FILHO, A. P. S.; TREZZI, M. M.; INOUE, M. H.

Sementes como fonte alternativa de substâncias químicas com atividade alelopática. Planta Daninha, Viçosa, v.29, n.3, p.709-716, 2011. DOI: http://doi.org/10.1590/S0100$\underline{83582011000300025}$

TAIZ, L.; ZEIGER, E.. Fisiologia vegetal. 5 ed. Porto Alegre: Artmed, 2013.

TEIXEIRA, R. A.; POLETTO, R.. Efeito alelopático de plantas tóxicas sobre a germinação e crescimento inicial do pepino. Revista Científica Eletrônica de Agronomia, Garça, v.25, n.1, p.38-47, 2014

ZENG, R. S.. Allelopathy: the solution is indirect. Journal of Chemical Ecology, v.40, n.6, p.515-516, 2014. DOI: http://doi.org/10.1007/s10886-014-0464-7

ZIMDAHL, R. L.. Fundamentals of Weed Science. 3 ed. London: Academic Press, 2007.

A CBPC - Companhia Brasileira de Produção Científica (CNPJ: 11.221.422/0001-03) detém os direitos materiais desta publicação. Os direitos referem-se à publicação do trabalho em qualquer parte do mundo, incluindo os direitos às renovações, expansões e disseminações da contribuição, bem como outros direitos subsidiários. Todos os trabalhos publicados eletronicamente poderão posteriormente ser publicados em coletâneas impressas sob coordenação da Sustenere Publishing, da Companhia Brasileira de Produção Científica e seus parceiros autorizados. Os (as) autores (as) preservam os direitos autorais, mas não têm permissão para a publicação da contribuição em outro meio, impresso ou digital, em português ou em tradução. 